\title{
Identification of physicians providing comprehensive primary care in Ontario: a retrospective analysis using linked administrative data
}

\author{
Susan E. Schultz MA MSc, Richard H. Glazier MD MPH
}

\section{Abstract}

Background: Given the changing landscape of primary care, there may be fewer primary care physicians available to provide a broad range of services to patients of all age groups and health conditions. We sought to identify physicians with comprehensive primary care practices in Ontario using administrative data, investigating how many and what proportion of primary care physicians provided comprehensive primary care and how this changed over time.

Methods: We identified the pool of active primary care physicians in linked population-based databases for Ontario from 1992/93 to 2014/15. After excluding those who saw patients fewer than 44 days per year, we identified physicians as providing comprehensive care if more than half of their services were for core primary care and if these services fell into at least 7 of 22 activity areas. Physicians with $50 \%$ or less of their services for core primary care but with more than $50 \%$ in a single location or type of service were identified as being in focused practice.

Results: In 2014/15, there were 12891 physicians in the primary care pool: 1254 (9.7\%) worked fewer than 44 days per year, 1619 $(12.6 \%)$ were in focused practice, and $1009(7.8 \%)$ could not be classified. The proportion in comprehensive practice ranged from $67.5 \%$ to $74.9 \%$ between $1992 / 93$ and $2014 / 15$, with a peak in $2002 / 03$ and relative stability from $2009 / 10$ to $2014 / 15$. Over this period, there was an increase of $8.8 \%$ in population per comprehensive primary care physician.

Interpretation: We found that just over two-thirds of primary care physicians provided comprehensive care in 2014/15, which indicates that traditional estimates of the primary care physician workforce may be too high. Although implementation will vary by setting and available data, this approach is likely applicable elsewhere.

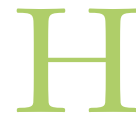
ealth human resource planning is challenging, given the need to project patient demand for service as well as the supply of different types of health care workers, their roles and their distribution in a jurisdiction. ${ }^{1}$ Primary care physicians are among the most commonly visited health care providers in most developed countries, and it is important to understand how to balance supply with future demand. The Institute of Medicine definition of primary care is understood as "the provision of integrated, accessible health care services by clinicians who are accountable for addressing a large majority of personal health care needs, developing a sustained partnership with patients and practicing in the context of family and community."

Primary care physicians' roles are many. Past research has focused on urban-rural and remote distribution of these phy- sicians $^{3}$ and on roles across settings such as offices, homes, hospitals, delivery rooms, emergency departments and longterm care homes. ${ }^{4-7}$ However, over the past $2-3$ decades, there has been a well-documented exodus of primary care physicians from many roles outside of the primary care office. ${ }^{4,5,7} \mathrm{In}$ that context, comprehensiveness has also come to focus on the range of services provided within the office setting, where

\section{Competing interests: None declared.}

This article has been peer reviewed.

Correspondence to: Richard Glazier, rick.glazier@ices.on.ca CMAJ Open 2017. DOI:10.9778/cmajo.20170083 
some primary care physicians limit their practice to services such as psychotherapy or sports medicine, with several focused areas of practice supported by professional bodies. ${ }^{8}$ Although these services are needed, there may consequently be fewer primary care physicians available to provide a broad range of services to patients of all age groups and health conditions. Health care planners need to take these patterns of care provision into account. Given the changing landscape of primary care, we propose an empirical approach to the definition of "comprehensive primary care" using administrative data. We could not rely on previous definitions as they focused only on settings ${ }^{7}$ or depended on self-reported services or coding limited to specific payers and not available for the entire population. ${ }^{6}$ We investigated how many and what proportion of primary care physicians in Ontario provided comprehensive primary care and how this changed over time. We also sought to investigate what roles physicians who did not provide comprehensive primary care played.

\section{Methods}

\section{Data sources}

We carried out this study using data sets that were linked with the use of unique, encoded identifiers and analyzed at the Institute for Clinical Evaluative Sciences. The Ontario Health Insurance Plan (OHIP) is a database of physician billings and "shadow-billings" based on the fee-for-service model. Shadow billings are submitted by physicians paid through alternative funding arrangements for which they may receive incentives of $10 \%-30 \%$ of the full fee. The OHIP Corporate Provider Database provides physician characteristics, including affiliation with a primary care patient enrolment model. In Ontario, these models represent types of patient-centred medical homes with the common characteristics of blended payments, formal patient enrolment, and incentives and bonuses for preventive care and chronic disease management. ${ }^{9}$ The Institute for Clinical Evaluative Sciences Physician Database comprises information from the Ontario Physician Human Resource Data Centre, the OHIP Corporate Provider Database and OHIP billings. We used it to determine physician specialty and active status.

\section{Definitions}

\section{Pool of primary care physicians}

The process of identifying primary care physicians in comprehensive practice began with defining the "pool" of primary care physicians. Using the specialty information available in Institute for Clinical Evaluative Sciences' administrative data, we determined that the primary care pool included 1) all physicians whose self-reported specialty was general practitioner or family physician plus 2) those whose self-reported specialty was not general practitioner/family physician but whose "functional specialty," that is, their practice pattern as defined by their fee-for-service billings, most closely matched those of a general practitioner/family physician. Also included with this latter group were specialists with full-time affiliation with a patient enrolment model. Other specialists such as general internists or gynecologists were not included, as previous work showed that they do not provide primary care in Ontario. ${ }^{10}$

\section{Core primary care services and activity areas}

To identify comprehensive primary care practice, we began by examining the pattern of billing by primary care physicians in order to identify core primary care services. We set 2 criteria that a billing code had to meet to be included in the list of core primary care services for a given year: 1) $80 \%$ or more of all billings for that code had to be submitted by physicians in the primary care pool and 2) total primary care billings for the code had to represent at least $0.1 \%$ of all billings by primary care physicians for that year. This represents $70 \%-80 \%$ of all services provided by primary care physicians, depending on the year.

A separate list was generated for each year from 1992/93 to 2014/2015, usually consisting of 30-40 billing codes. The combined list for all years can be found in Appendix 1 (available at www.cmajopen.ca/content/5/4/E856/suppl/DC1). Twenty-three billing codes were included in every year. A further 45 billing codes were included in some years but not others, generally because they were new or had been discontinued.

A physician billing more than $50 \%$ for core primary care services could still be providing a narrow range of services and thus not be truly providing comprehensive care. To address this issue, we grouped core primary care services into 22 activity areas. Codes that could not be classified were excluded. These areas are roughly comparable to both those developed by the American Board of Family Medicine, which were derived from Medicare claims, ${ }^{6}$ and those reported by Canadian primary care physicians, ${ }^{11}$ but in this case they reflect billing codes and patterns in Ontario.

\section{Comprehensiveness threshold}

Finally, it was necessary to define a threshold for number of activity areas necessary for a physician to be considered to be providing comprehensive primary care. We plotted the proportion of physicians with billings in each activity area according to their total number of activity areas. Figure 1 shows the results for the 10 most common service-related activity areas plus the 4 location-related activity areas across all years. A minimum threshold of 7 activity areas was chosen. It would be unlikely for a physician to be practising in a limited range of venues (e.g., hospitalists) or providing a narrow range of services (e.g., general practitioner psychotherapists) and meet the threshold of 7 activity areas.

The detailed steps for identifying physicians in comprehensive primary care practice are found in Appendix 2 (available at www.cmajopen.ca/content/5/4/E856/suppl/DC1).

\section{Ethics approval}

The Research Ethics Board of Sunnybrook Health Sciences Centre approved this study. 


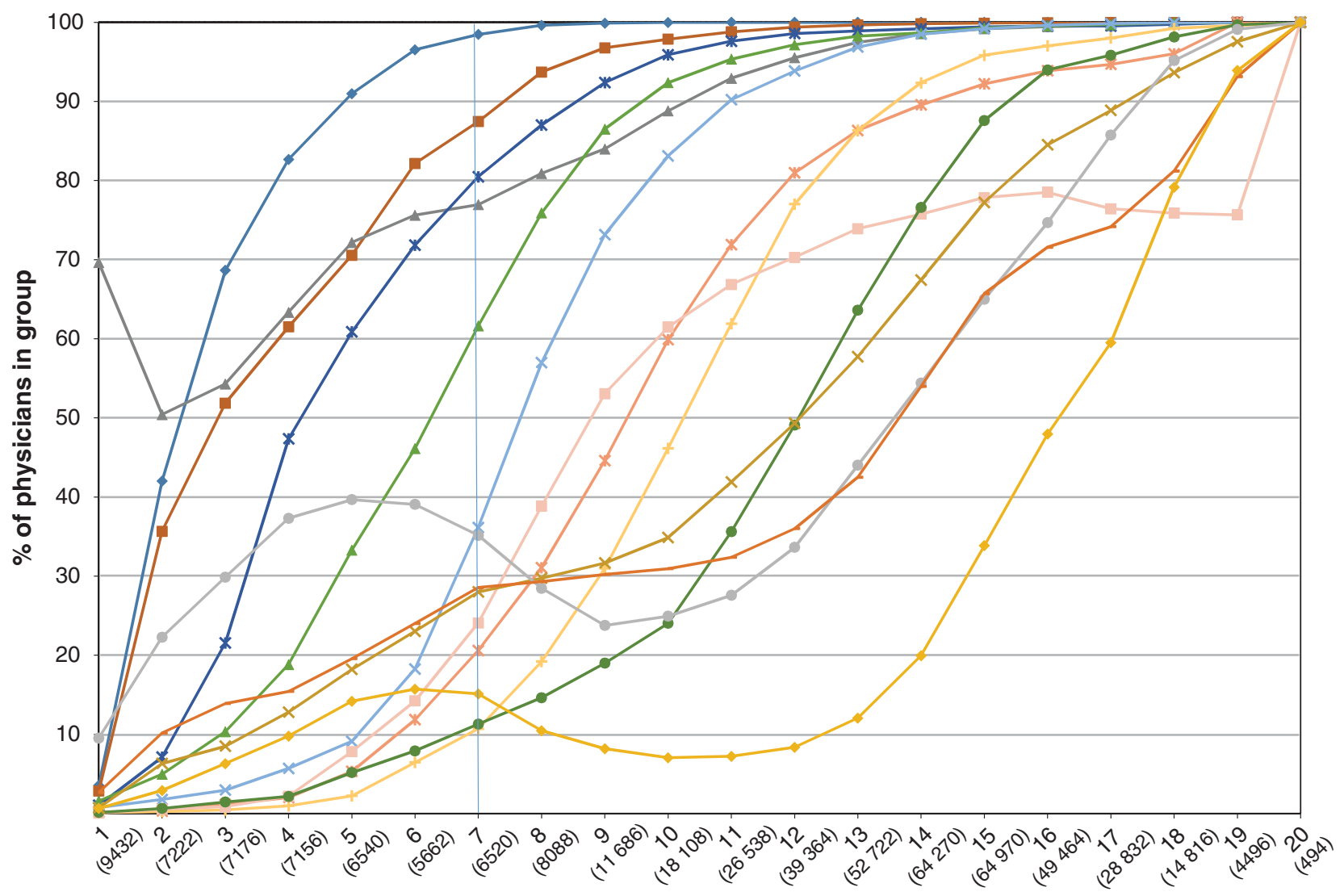

No. of activity areas (no. of physicians in group)

$\rightarrow$ Intermediate assessment $\rightarrow$ Minor assessment $\rightarrow$ Mental health/addiction $\rightarrow$ General assessment $\rightarrow$ Injection
$*$ Immunization $\rightarrow$ Papanicolaou smear $\longrightarrow$ Periodioc health examination - Allergy shots $\rightarrow$ Anticoagulant therapy
$\rightarrow$ House call $\rightarrow$ Hospital $\longrightarrow$ Emergency department $\longrightarrow$ Long-term care

Figure 1: Proportion of primary care physicians with billings in selected activity areas, grouped by total number of primary care activity areas. Blue vertical line represents minimum threshold of activity areas necessary for a physician to be considered to be providing comprehensive primary care.

\section{Results}

In addition to tracing the decision pathway used to define physicians providing comprehensive primary care, Figure 2 shows the number of physicians who met or did not meet the criteria at each step in 2014/15, distinguishing between those in medical home models (patient enrolment model) and those who were not. A total of 29467 physicians were active at the beginning of 2014/15. The initial primary care pool consisted of 12891 physicians who were general practitioners/family physicians by either self-report or functional specialty plus 149 "specialists" with full-time affiliation with patient enrolment model. Of the 12891 general practitioners/family physicians, $1254(9.7 \%)$ were excluded because they had not worked the minimum 44 days during the year, and a further
$2252(17.5 \%)$ did not have more than $50 \%$ of their services defined as core primary care, leaving 9385 general practitioners/family physicians. The core primary care billings fell into 7 or more activity areas for $8828(68.5 \%)$ of the 12891 general practitioners/family physicians, representing the total number of primary care physicians in comprehensive practice in 2014/15. After checking for focused practice, we found that $1619(57.6 \%)$ of the remaining 2809 physicians met this definition; the remainder did not meet any of our thresholds.

Figure 3 and Appendix 3 (available at www.cmajopen.ca/ content/5/4/E856/suppl/DC1) show how the distribution of active physicians by type and year changed between 1992/93 and $2014 / 15$. The proportion in comprehensive practice ranged from $67.5 \%$ to $74.9 \%$ over the study period, with a peak in $2002 / 03$ and relative stability from $2009 / 10$ to 


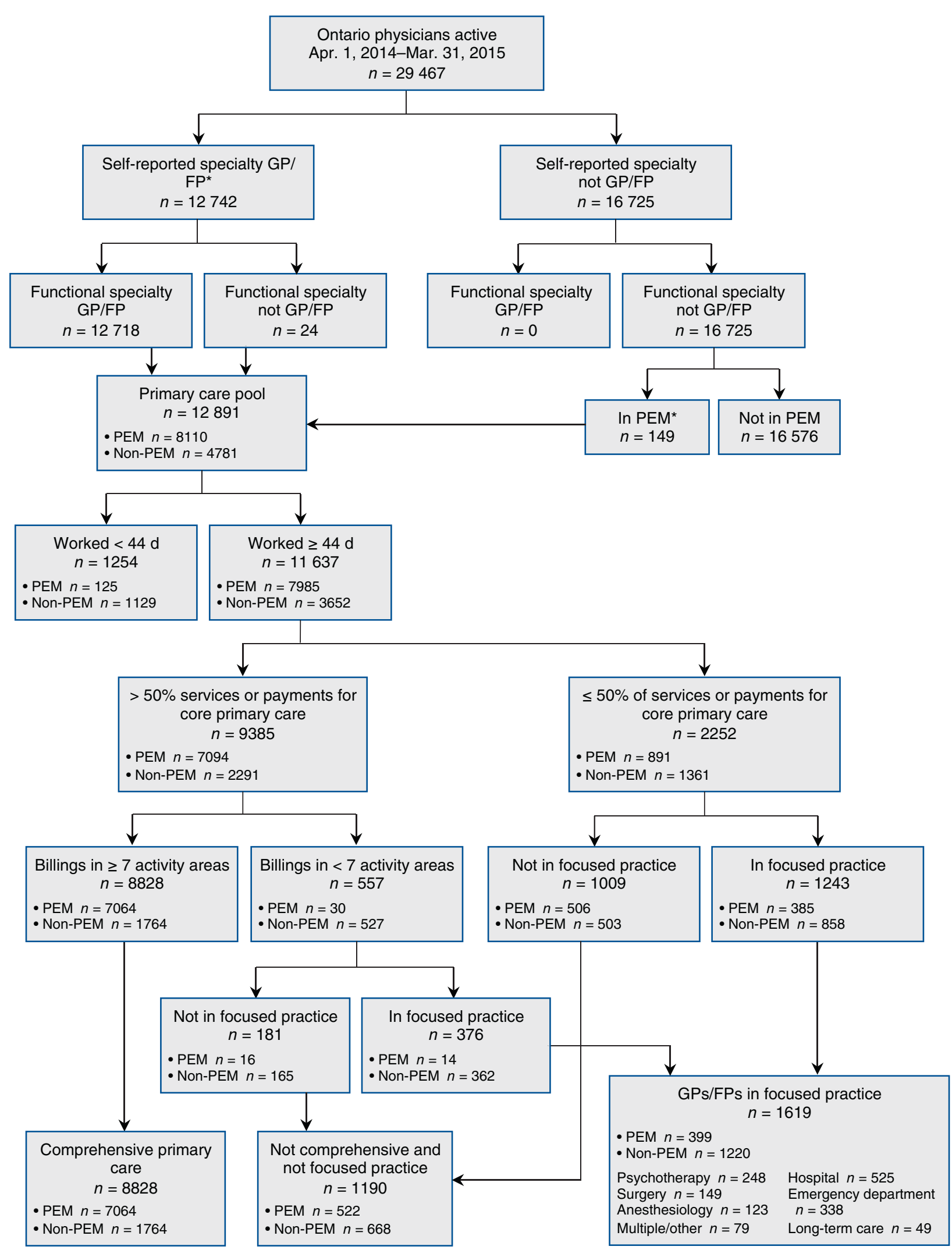

Figure 2: Flow diagram showing identification of physicians providing comprehensive primary care. *Primary care pool. Note: GP/FP $=$ general practitioner/family physician, $\mathrm{PEM}=$ patient enrolment model. 


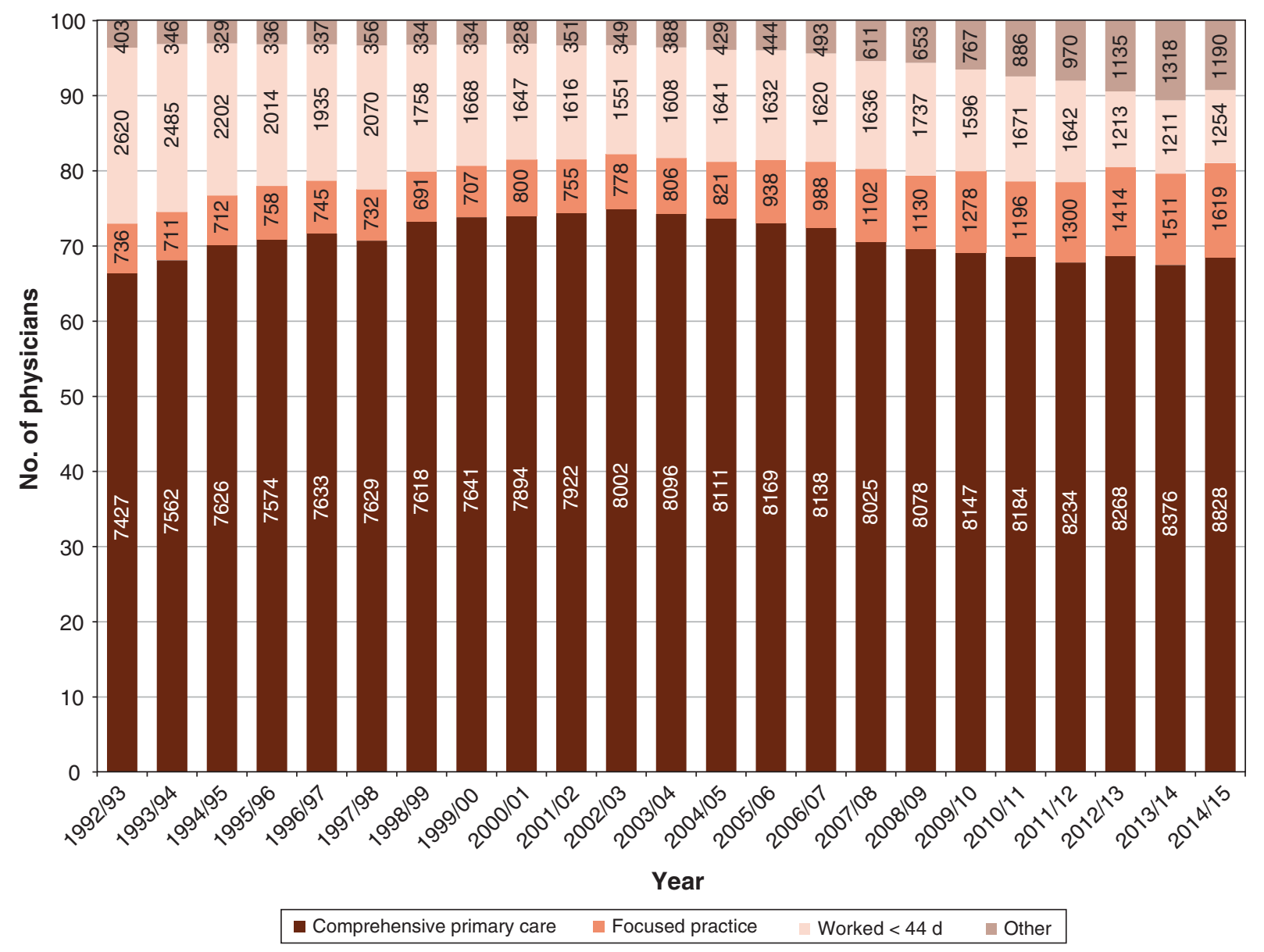

Figure 3: Distribution of primary care physicians by practice type, Ontario, 1992/93-2014/15.

2014/15, at or slightly below $70 \%$. Of note, the primary care pool itself as a proportion of all active Ontario physicians declined from $51.9 \%$ to $43.7 \%$ over the study period. Although the total number of active physicians in Ontario increased by $39.8 \%$, most of this increase was among specialists, whose numbers increased by $63.3 \%$, compared to $17.9 \%$ for the primary care pool and $18.9 \%$ for those in comprehensive primary care practice. The population per active physician decreased by $7.4 \%$, whereas there was an increase of $8.8 \%$ in population per comprehensive primary care physician. The proportion who worked fewer than 44 days during the year declined over time, whereas the proportion in focused practice and "Other" groups increased.

The distribution of primary care physicians by practice type and age group for 3 selected years (1993/94, 2003/04 and $2013 / 14$ ) is shown in Figure 4. Between 1993/94 and $2013 / 14$, the proportion of physicians aged less than 40 years declined, from $45.3 \%$ to $23.5 \%$, whereas the proportion older than 60 grew, from $13.7 \%$ to $26.6 \%$ (data not shown). The proportion in comprehensive practice fluctuated over time in each age group but was generally lower in 2013/14 than in the other 2 years, whereas the proportion in focused practice increased in all age groups.

Figure 5 shows the distribution by practice type and sex in 1993/94, 2003/04 and 2013/14. The proportion of physicians who provided comprehensive care was nearly identical for men and women across all 3 years. However, there tended to be a higher proportion of women working fewer than 44 days in the year and a higher proportion of men in focused practice. For both sexes, the proportion in focused practice increased over time.

\section{Interpretation}

This study's major contribution is its attempt to categorize primary care physicians according to whether they provide comprehensive care. We found that, in a large Canadian single-payer setting, just over two-thirds of primary care physicians provided comprehensive care, a proportion that declined from about $75 \%$ after 2003/04. The main implication of these results is for health human resources planning, as a "head-count" approach to planning ${ }^{1}$ would have 


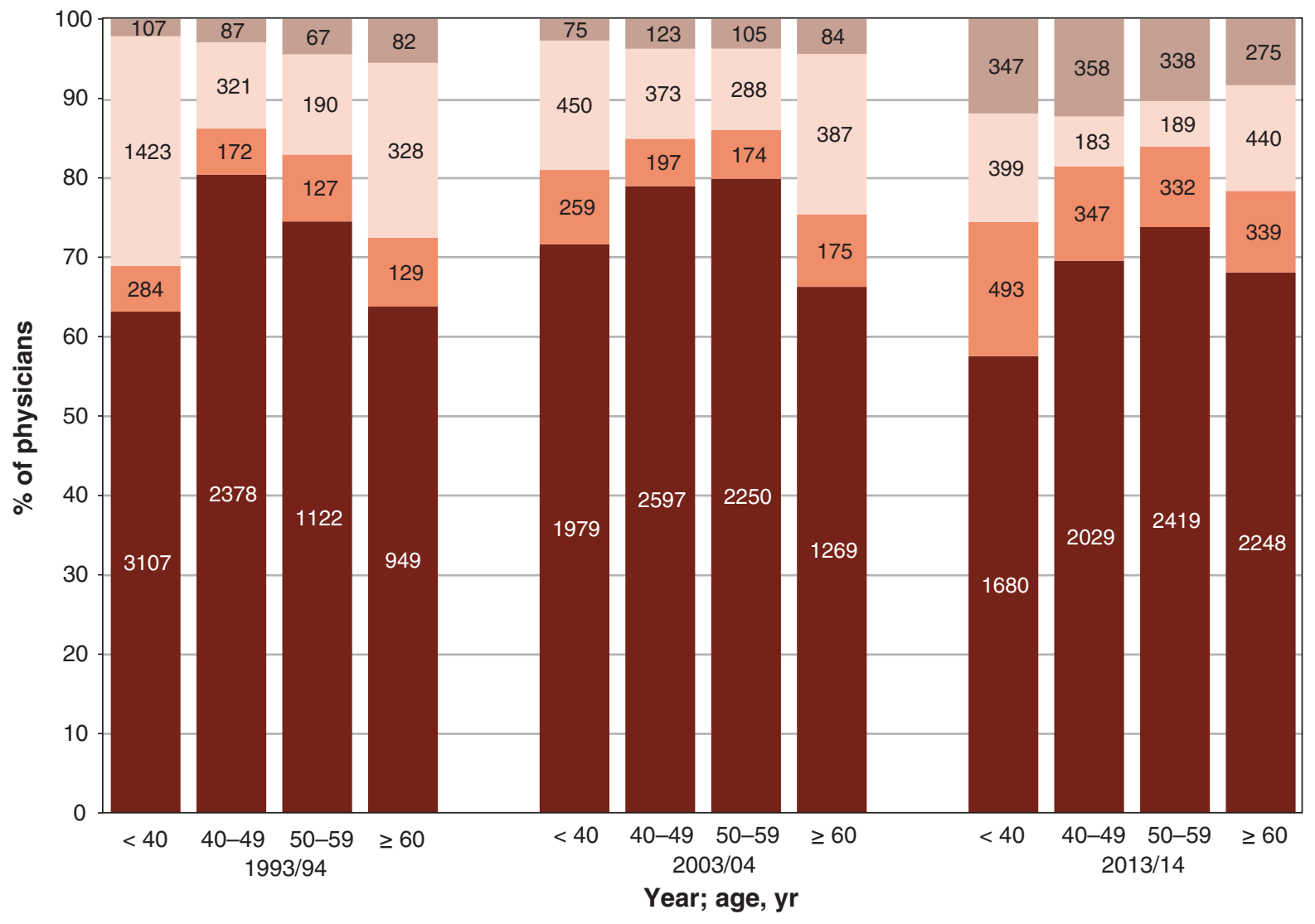

Comprehensive primary care practice

Focused practice

Worked $<44 \mathrm{~d}$

Other

Figure 4: Distribution of primary care physicians by practice type and age group, 1993/94, 2003/04 and $2013 / 14$.

overestimated physician capacity to provide comprehensive primary care by about a third in our setting. Many physicians who would traditionally be counted in primary care were in fact in focused practice such as hospitalist care, emergency medicine or psychotherapy, and a substantial proportion were relatively inactive. We also found similar growth over time in the overall primary care pool and in physicians providing comprehensive primary care, with both groups lagging behind the overall increase in physician supply, which was largely driven by specialists. Despite an increase in physician numbers, population growth has meant that the availability of physicians providing comprehensive primary care to the Ontario population declined substantially over time.

Comprehensiveness is an imprecise concept in primary care, given the broad range of care provided in community and institutional settings and increasingly by telephone, email and other electronic means. Not surprisingly, numerous methods have been used to define and measure comprehensiveness that have focused on settings of care, ${ }^{7}$ types of care provided ${ }^{12-14}$ or a mix of settings, types of care and procedures. ${ }^{6}$ Comprehensiveness can also be measured from a number of perspectives, including provider report, patient report and administrative claims. Each of these methods has strengths but also methodological shortcomings, ${ }^{11,12,14-16}$ and data derived from different perspectives may not correlate well. ${ }^{6,15,16}$ Nonetheless, measurement from different perspectives has had similar relations with outcomes. ${ }^{6}$ Although challenging to measure, comprehensiveness of care is a cornerstone of primary care provi$\operatorname{sion}^{17,18}$ and has been shown to be associated with decreased health costs and hospital admissions. ${ }^{6}$

The activity areas used in this paper included locations of care such as the hospital and the patient's home, but most related to the scope of office-based care. A decrease in primary care physician roles outside of the primary care office in the last 2-3 decades has been reported. ${ }^{4,5,7}$ Office-based care also relates strongly to the concept of the Triple Aim of enhancing patient experience, improving population health and reducing costs, ${ }^{19}$ as well as to the Patient-Centered Medical Home in the United States ${ }^{20}$ and the Patient's Medical Home in Canada. ${ }^{21}$ Quality-improvement efforts in primary care also tend to be focused on office redesign and organization of health care teams in office settings. ${ }^{19}$ 


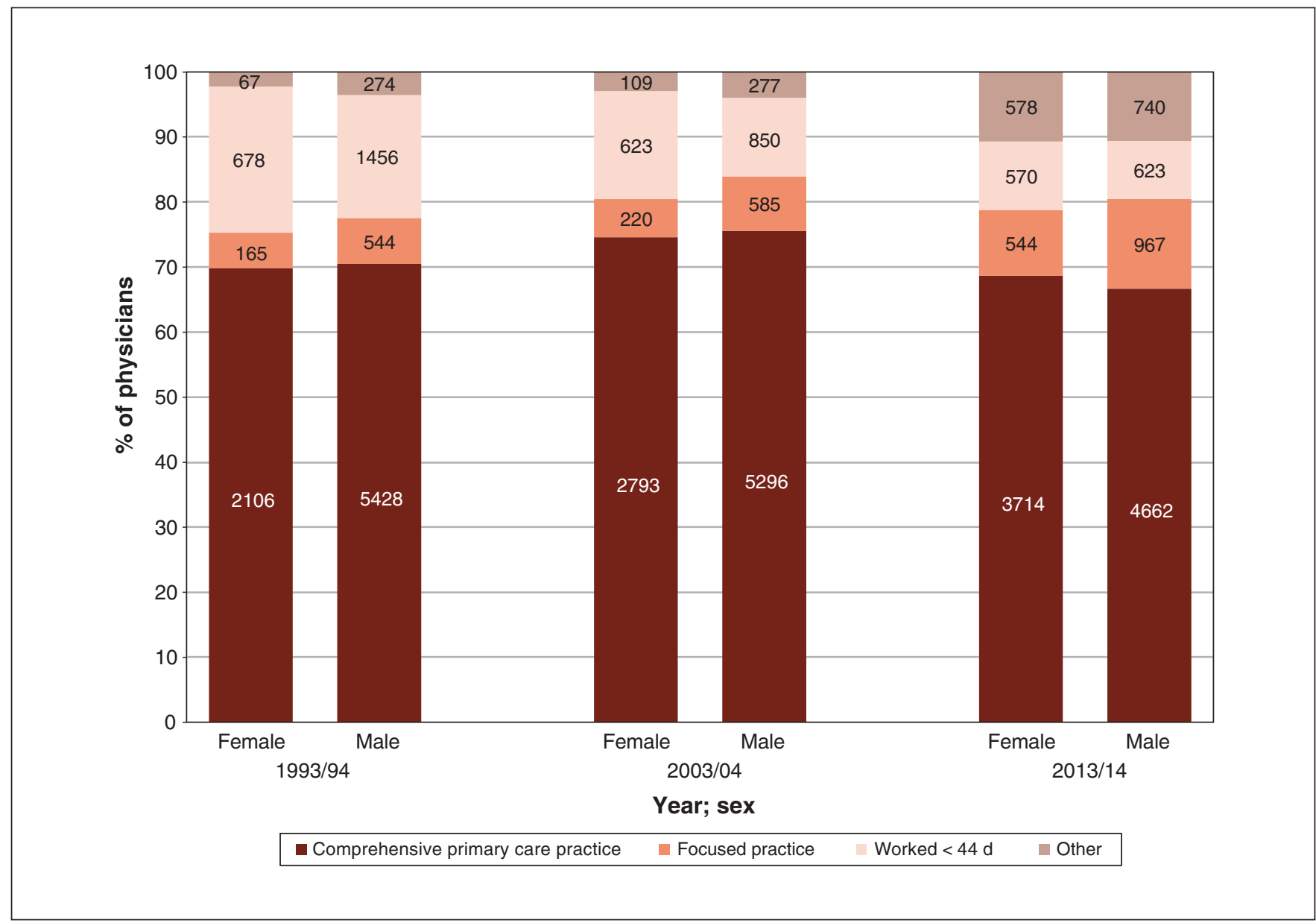

Figure 5: Distribution of primary care physicians by practice type and sex, Ontario, 1993/94, 2003/04, 2013/14.

\section{Limitations}

This study used population-based data from a large singlepayer jurisdiction and has the strength of being relatively complete for physician billing claims and population coverage. Nonetheless, administrative data such as these have several important limitations. In this setting, claims data cover only the permanent resident population of Ontario, and, as such, some recent immigrants and refugees, temporary visitors and those without documentation of their residency status may have been missed. The available data also did not include primary care nurse practitioners or physician assistants, nor did they include physicians at community health centres, who are salaried and provide primary care to about $2 \%$ of Ontario's population..$^{22}$ In addition, the data did not include most patient contacts by telephone, email or other electronic means, as billing codes do not exist for most of these services. Diagnostic coding in administrative data has been shown to be inadequate for measuring comprehensiveness. ${ }^{15}$ For that reason, we chose to establish primary care activity areas using fee codes that are expected to be fairly complete, as they are the basis for physician payment. The 22 activity areas used in this research were developed with the use of Ontario's core primary care fee codes, and, although this approach is likely applicable elsewhere, the details of coding and claims data would need to be adapted to other settings. Our approach classified primary care physicians as providing or not providing comprehensive care, in contrast to the use of scales or scores. ${ }^{6,12,16}$ This dichotomous approach was designed to inform health human resource planning but did not include part-time comprehensive care provided by physicians who spend their time in multiple settings and may therefore have underestimated the total amount of comprehensive care.

\section{Conclusion}

We found that just over two-thirds of Ontario primary care physicians provided comprehensive care in $2014 / 15$ and that this proportion declined slightly over the previous decade, along with a substantial decline in the availability of primary care physicians in comprehensive practice to the growing Ontario population. The implication of these findings for health human resource planning is that traditional primary care estimates may be too high if the goal is to provide comprehensive primary care. Further analyses would be valuable for establishing the supply of providers of comprehensive primary care, including interprofessional team members, in 
relation to population health needs and for understanding the applicability of our approach using linked administrative data to other jurisdictions. We conclude that it is feasible to identify which primary care physicians provide comprehensive primary care and that the findings are likely to be of value in health human resource planning for population needs.

\section{References}

1. Physicians in Canada, 2014: summary report. Ottawa: Canadian Institute for Health Information; 2015. Available: https://secure.cihi.ca/free_products/ Summary-PhysiciansInCanadaReport2014 EN-web.pdf (accessed 2017 Nov. 1).

2. Donaldson M, Yordy K, Vanselow N. Defining primary care: an interim report. Washington: National Academy Press; 1994. Available: https://www. nap.edu/read/9153/chapter/1 (accessed 2017 Nov. 1).

3. Viscomi M, Larkins S, Gupta TS. Recruitment and retention of general practitioners in rural Canada and Australia: a review of the literature. Can $\mathcal{F}$ Rural Med 2013;18:13-23.

4. Petterson S, Peterson L, Phillips RL, et al. One in fifteen family physicians principally provide emergency or urgent care. 7 Am Board Fam Med 2014;27: 447-8.

5. Rayburn WF, Petterson SM, Phillips RL. Trends in family physicians performing deliveries, 2003-2010. Birth 2014;41:26-32.

6. Bazemore A, Petterson S, Peterson LE, et al. More comprehensive care among family physicians is associated with lower costs and fewer hospitalizations. Ann Fam Med 2015;13:206-13.

7. Chan BT. The declining comprehensiveness of primary care. CMA7 2002;166: 429-34.

8. Section of communities of practice in family medicine. Toronto: College of Family Physicians of Canada; 2015. Available: www.cfpc.ca/CPFM/ (accessed 2017 May 27).

9. Hutchison B, Glazier R. Ontario's primary care reforms have transformed the local care landscape, but a plan is needed for ongoing improvement. Health Aff (Millwood) 2013;32:695-703.

10. Manuel DG, Maaten S, Thiruchelvam D, et al. Primary care in the health care system. In: Jaakkimainen L, Upshur REG, Klein-Geltink JE, et al., editors. Primary care in Ontario: ICES atlas. Toronto: Institute for Clinical Evaluative Sciences; 2006. Available: https://www.ices.on.ca/flip-publication/primary -care-2006/files/assets/basic-html/index.html\#1 (accessed 2017 Nov. 1).

11. Wong E, Stewart M. Predicting the scope of practice of family physicians. Can Fam Physician 2010;56:e219-25.

12. Ie K, Ichikawa S, Takemura YC. Development of a questionnaire to measure primary care physicians' scope of practice. BMC Fam Pract 2015;16:161.

13. Bazemore AW, Petterson S, Johnson N, et al. What services do family physicians provide in a time of primary care transition? 7 Am Board Fam Med 2011;24: 635-6.

14. Shi L, Starfield B, Xu J. Validating the Adult Primary Care Assessment Tool. 7 Fam Pract 2001;50:61W-75W.
15. Katz A, Halas G, Dillon M, et al. Describing the content of primary care: limitations of Canadian billing data. BMC Fam Pract 2012;13:7.

16. Haggerty JL, Beaulieu MD, Pineault R, et al. Comprehensiveness of care from the patient perspective: comparison of primary healthcare evaluation instruments. Healthc Policy 2011;7:154-66.

17. Starfield B. Primary care: balancing health needs, services and technology. New York: Oxford University Press; 1998

18. Bodenheimer T, Ghorob A, Willard-Grace R, et al. The 10 building blocks of high-performing primary care. Ann Fam Med 2014;12:166-71.

19. Triple Aim for populations. Toronto: Institute for Healthcare Improvement; 2015. Available: www.ihi.org/Topics/TripleAim/Pages/default.aspx (accessed 2017 May 27).

20. The patient-centered medical home (PCMH). Leawood (KS): American Academy of Family Physicians; 2016. Available: www.aafp.org/practice-management/ transformation/pcmh.html (accessed 2017 May 27).

21. A vision for Canada: family practice - the patient's medical home. Mississauga (ON): College of Family Physicians of Canada; 2011. Available: www.cfpc. ca/A_Vision_for_Canada_Family_Practice_2011/(accessed 2017 May 27).

22. Glazier RH, Rayner J, Kopp A. Examining community health centres according to geography and priority populations served, 2011/12 to 2012/13: an ICES chartbook. Toronto: Institute for Clinical Evaluative Sciences; 2015. Available: https://www.ices.on.ca/Publications/Atlases-and-Reports/2015/ Examining-Community-Health-Centres (accessed 2017 Nov. 1).

Affiliations: Institute for Clinical Evaluative Sciences (Schultz, Glazier); Department of Family and Community Medicine (Glazier), University of Toronto and St. Michael's Hospital, Toronto, Ont.

Contributors: Susan Schultz was primarily responsible for data analysis. Both authors contributed to the study conception and design, and interpretation of the data, drafted the manuscript, revised the manuscript critically for important intellectual content, gave final approval of the version to be published and agreed to be accountable for all aspects of the work.

Funding: Richard Glazier is supported as a Clinical Scientist in the Department of Family and Community Medicine at the University of Toronto and at St. Michael's Hospital.

Disclaimer: This study was supported by the Institute for Clinical Evaluative Sciences (ICES), which is funded by an annual grant from the Ontario Ministry of Health and Long-Term Care (MOHLTC). The opinions, results and conclusions reported in this article are those of the authors and are independent from the funding sources. No endorsement by the ICES or the MOHLTC is intended or should be inferred.

Supplemental information: For reviewer comments and the original submission of this manuscript, please see www.cmajopen.ca/content/5/4/ E856/suppl/DC1. 